\title{
Intelligent Services for Building Information Modeling - Assessing Variable Input Weather Data for Building Simulations
}

\author{
Constantinos A. Balaras*, Simon Kontoyiannidis, Elena G. Dascalaki and Kaliopi G. Droutsa
}

\begin{abstract}
Group Energy Conservation, Institute for Environmental Research \& Sustainable Development, National Observatory of Athens, I. Metaxa \& Vas. Pavlou, GR-15236 Palea Penteli, Greece
\end{abstract}

\begin{abstract}
Building Information Modeling (BIM) for optimizing the total lifecycle cost of buildings is a challenge even today. Inadequate software interoperability, high costs as a result of the fragmented nature of the building industry, lack of standardization, inconsistent technology adoption among stakeholders are just some of the obstacles that architects and engineers face. However, optimization requires a structured procedure that enables continuous changes in design variables and assessment on energy consumption. A holistic building design and construction are already introduced in Europe through the energy performance of buildings directive (EPBD). The requirements have been strengthened by the EPBD recast for achieving cost optimal building designs for the life cycle of the building, moving towards nearly zero energy buildings by the end of the decade. BIM and intelligent services could play a crucial role in these efforts with improved visualization and productivity due to easy retrieval of information, increased coordination of data and exchange of information, all leading to a reduced cost for the design of energy efficient buildings. An ongoing European research project aims to contribute to these needs by developing a Virtual Energy Laboratory that will support building energy performance simulations taking into account the stochastic nature of input parameters and processes. This will be supported by information communication technology features utilizing the necessary computational power through cloud computing. This paper presents an overview of the ongoing efforts and focuses on results for assessing the impact of different input weather and climate data that are pertinent in building load and energy performance calculations.
\end{abstract}

Keywords: Buildings, building information modeling (BIM), energy conservation.

\section{INTRODUCTION}

Building Information Modeling (BIM) is the process of generating and managing building data during its lifecycle. Typically it uses three-dimensional, real time, dynamic building modeling software to increase productivity in building design and construction. On the other hand, energy simulation tools offer insight into the behaviors associated with a given design, and provide an assessment of gross energy, breakdown of different end-uses, as well as estimated operating costs. These tools also require significant amounts of non-project specific information [1], including details that may affect, for example, incident solar radiation and any objects or effects that may restrict exposure to solar radiation or views of existing structures, such as geographic location, climatic conditions, surrounding structures, or topography. This information is not typically carried within BIM design tools but by the secondary simulation tools. These distributed datasets often introduce management - level problems, such as determining which analysis run gave which results and based on which version of the design. In this respect, repositories can play an important role. At the moment, most of the information generated by these tools must be regenerated in the transfer to a BIM tool. The ongoing development

\footnotetext{
*Address correspondence to this author at the Group Energy Conservation, Institute for Environmental Research \& Sustainable Development, National Observatory of Athens, I. Metaxa \& Vas. Pavlou, GR-15236 Palea Penteli, Greece; Tel: +30 210 8109152; E-mail: costas@noa.gr
}

of a Virtual Energy Laboratory (VEL) investigates the possibilities to increase the exchange and coordination of information data between a standard BIM and Industry Foundation Classes (IFC) model and a multi-model environment of related external information resources, supported by the necessary computational power provided by cloud computing.

Since 2006, the European Directive 2002/91/EC on the energy performance of buildings (EPBD) has introduced a more holistic building design and construction approach to new and existing European buildings that are subject to major renovations. Accordingly, to obtain a building permit, an energy design study is required that introduces an integrated design approach, mandating a team effort among architects and engineers. As a first step, the design should take into account proper building space layout and orientation (exploiting of local climate conditions), configuring the surrounding space (improving microclimate), openings for different orientations depending on direct solar gains, daylight and ventilation requirements, arranging interior spaces depending on use and the comfort requirements, integrating one passive solar system, providing proper solar protection, integrating natural ventilation and exploiting daylight for securing visual comfort. Over 40 European (EN) and international (ISO) standards have been published to support EPBD implementation and are being used in many European Union (EU) Member States (www.cen.eu).

In addition, the building's envelope should meet minimum thermal insulation levels, while addressing specific 
requirements for the design of heating, ventilation and airconditioning (HVAC) installations and automation systems, in order to meet the minimum building energy performance obligations. This is documented by the energy performance certificate (EPC) that documents the building's energy performance and facilitates comparison between buildings and benchmarking based on distinct energy classes. EPCs must be issued when buildings are constructed, sold, or rented out and they are valid for up to ten-years. At a minimum, all new buildings throughout Europe, meet the minimum energy performance requirements and are better than a minimum indicator (building ranking or class). However, even for historic buildings there are opportunities of implementing energy conservation measures that respect the architectural heritage of buildings, improve the indoor environmental quality and enhance building functions in a cost-effective manner [2].

Overall, national EPBD transposition and implementation proved to be a major struggle throughout Europe. In particular, EPCs have been gradually introduced throughout Europe. Although there have been some long delays, it appears that since January 2009 the majority of EU Member States have set a mandatory requirement for issuing EPCs [3]. It is clear that European Directives like EPBD, despite the obstacles and delays, constitute the primary driving mechanism of national energy efficiency policies. This is also well documented by the findings of a recent expert study for the European Commission that was performed throughout Europe [4].

The recently published EPBD recast [5] strengthens the energy performance requirements and mandates that all new buildings must be nearly zero energy buildings as of January 2021. To support the implementation of the EPBD recast, the European Commission has issued a new standardization mandate to the European Committee for Standardization (CEN) for the elaboration and adoption of standards for a methodology calculating the integrated energy performance of buildings and promoting the energy efficiency of buildings [6]. The horizontal coordination of the work has been allocated to CEN-Technical Committee TC 371. Currently, CEN has initiated the second phase to revise the total set of EPB-standards. The Build-up platform is used as a public platform for easy access to relevant updates and information (www.buildup.eu/communities/epcalc).

At the same time, EU Member States introduce minimum energy use requirements for all HVAC systems, while the nearly zero or very low amount of energy required must, to a very significant level, be covered by renewable energy sources, combined heat and power generation or district heating and cooling. National minimum requirements for buildings and building components undergoing renovation are currently being defined on the basis of cost-optimal balance between the investment involved and the energy cost saved throughout the lifecycle of a building.

To facilitate this process, architects and engineers need to exchange data and share information of various formats, using heterogeneous tools with different functions and requirements for a plethora of input data. Generating, collecting, managing and efficiently exchanging large amount of data from different sources could be facilitated by BIM, provided that there is adequate software interoperability. Com- plementing these services with the necessary computational power for digital representation of physical and functional building characteristics as a shared knowledge resource, one may support the decision-making process from the conceptual building design stages to design, construction, operational life and eventual demolition.

Similar efforts for improving the energy performance of buildings and labeling, are underway throughout the world. For example, in the United States, several green building and energy efficiency rating systems and standards are available [7]. Also notable are the recent efforts of ASHRAE's Building Energy Quotient (bEQ), a building energy labeling program that allows the industry to zero-in on opportunities to lower building operating cost and make informed decisions to increase value [8]. Existing high performance and zero energy commercial buildings that produce as much energy as they use on an annual basis demonstrate real world solutions [9]. Even in regions where fossil fuels are abundant, there are issues and circumstances that encourage participation in these international trends, with energy efficient buildings in several countries [10].

The paper is structured in three parts. The first part presents a brief description of the BIM concept. The second part presents an overview of an ongoing European research project in an effort to provide intelligent services that will facilitate different users for exploiting BIM services and enhancing building design and analysis. The third part presents a case study, as a first step towards the investigation concerning the influence of weather and climate data on building load and energy performance calculations.

\section{BUILDING INFORMATION MODELING}

A BIM system is a $3 \mathrm{D}$ modeling system with data management, data sharing and data exchange that enables users to integrate and reuse the information of a building throughout its lifecycle [11]. Using parametric modeling it provides powerful mechanisms that can automate the generation of the building information. BIM models can be accurate at any scale, digitally readable and writable, and they can be automatically detailed and analyzed in ways that are not possible with physical scale models.

There are several definitions of BIM in the literature. The National BIM Standard Initiative [12] defines BIM as: "a digital representation of physical and functional characteristics of a facility. A BIM is a shared knowledge resource for information about a facility forming a reliable basis for decisions during its life-cycle; defined as existing from earliest conception to demolition". It classifies BIM in three categories, namely: Product, Collaborative Process and Facility. The first one is an intelligent digital representation of the building using parametric rules, the second one covers common market practices through automated process capabilities and open information standards, while the third concerns the information exchanges, workflows, and procedures. BIM is the computable representation of all the physical and functional characteristics of a building and it is related to the project information, which is intended to be a repository of information for the building owner/operator to use and maintain throughout the lifecycle of the building. Computer aided design software commonly assign three main features to 
BIMs: ability to store, share and exchange data (files or database); object oriented building model [13] controlled by parametric rules (change to any part of the design automatically reflects to all other parts); ability to link the data model to various types of analysis tools throughout building lifecycle. To facilitate data interchange between different BIM models, there is a trend towards interoperability between different BIM platforms using IFC definitions, an effort supported by the buildingSMART alliance (www.buildingsmartalliance.org). Software and hardware compatibility, different operating environments, and practical reluctance to invest in a costly "new" technology, are some of the obstacles that have refrained wide spread market penetration.

Apparently, BIM provides different benefits to the members of a building design and construction team or building operators and facility managers. Moving beyond 3D visualizations, adding project time planning (4D design) to visualize the entire construction sequence, incorporating specific material quantities and costs (5D design) to easily monitor construction costs, the design and construction teams can optimize their work. Again, the key is that they can all share data and a wide range of building design, construction and maintenance information that is all combined in one BIM model. The benefits continue even during follow-up phases, for example, during the commissioning phase, by capturing relevant information in the BIM model, so that it can be directly integrated in the owner's facility management software and readily accessible to building operators. Eventually, it may be possible to even incorporate monitoring or other building performance data.

\subsection{BIM Design and Analysis/Simulation}

As building design moves past the concept stage, systems require detailed specification. This is a critical phase, since the decisions made at this stage will have the greatest impact on the overall building's energy performance. For example, mechanical systems are sized depending on building envelope material and component selection, since they directly influence the loads. These tasks are usually undertaken through the collaboration of various engineering disciplines. Buildings must comply with several codes, e.g. structural, HVAC, electrical, etc. While each of their capabilities and the systems required to support them may have been identified during the building's conceptual design, their specification for conformance to codes or certifications require more detailed definition. Since the 1980 s, a large number of analysis tools based on building physics have been developed, long before the introduction of BIM. For the majority of these tools, a significant effort and time was required in order to prepare the necessary input data to run the models. With automated interfaces, a more efficient workflow is possible, allowing multiple experts from different disciplines to generate the final design. A proper interface between a BIM tool and a specific application assigns the necessary attributes and relations in the BIM tool, compiles an analytical model of the building geometry that contains the necessary data abstracted from the physical BIM model, and supports the data transfer by using a proper format for identifying information to ensure incremental updating on both sides of the exchange [14].
Almost all existing building analysis software tools require extensive preprocessing of the model geometry, defining building material properties and load conditions (internal heat gains, occupancy schedules, specific indoor conditions for heating or cooling). When BIM tools incorporate the above capabilities, the building geometry can be derived directly from the common model, material properties can be assigned automatically for each analysis and load conditions for an analysis can be stored, edited and applied. Nevertheless, building energy simulations usually have specific requirements [15]. For example, one dataset set for representing the external building envelope associated with incident solar radiation; a second set for representing the internal thermal zones and internal heat gains; and a third set for representing the HVAC installations [16]. Additional data preparation by the user, usually an energy expert, is also commonly required. By default, only the first of these data sets are represented in a typical BIM design tool.

\section{THE ISES PROJECT}

The challenge to develop information and communication technology building blocks that integrate, complement and empower existing tools for design and operation management are currently being investigated in the framework of an ongoing European research project (ISES). The goal is to facilitate simulation, assessment and optimization of building energy performance in variations of real life scenarios, acknowledging the stochastic nature of some input parameters. The main deliverable will be a Virtual Energy Laboratory (VEL) platform that builds on existing knowledge for improving state-of-the-art tools [17] to facilitate a holistic analysis of building energy performance and to make informed design decisions. The functional structure will include several tiers. The domain modeling and input will combine several tools and databases for modeling the building, its envelope components, climate and occupancy. A multi-model combiner and simulation configurator will use an easy to use graphical interface to automatically combine different models to meet the specific user requirements.

For the development of the VEL, emphasis is placed on three tasks: Consideration of the stochastic nature of the energy performance and consumption profiles in the building's lifecycle; Balanced design of the involved new building products and components, taking into account their functionality and behavior for various possible lifecycle demands; and Integration of these products/ components in the facility, taking into account various alternatives with regard to location, usage, costs etc. Each of these tasks will require several iteration cycles in order to reach an optimal balanced solution. Since the required calculations are very complex, individual computers (running desktop applications) could take several hours to execute. To overcome this limitation, the necessary computational power for the simulations will be provided by cloud computing. The cloud system uses the processing power of all available computers on the back end, significantly speeding up the calculations. The evaluation and prioritization of the multi-model results will be facilitated by supporting services (i.e. multi-model filter, navigator, evaluator and manager) that provide easy user access to the simulation results for comparison and decision making. Clients would be able to access their applications and data 
from anywhere, at any time. An intelligent access controller and system management will provide automated access to all available information (e.g. BIM, databases, product catalogues), middle-ware services and cloud environment. Finally, a model and system ontology will be responsible for the storage, access and management of the VEL system model. This description-logic based ontology will describe the VEL system and its components, along with the various model schemas, possible combinations, automation algorithms, evaluation and feedback control information.

\subsection{Stochastic Analysis}

The stochastic analysis will focus on determining the probabilistic distribution of an outcome that relies on multiple probable scenarios [18]. The goal is to produce not only one answer, but rather a range of answers over which the results vary as a function of probability of occurrence and also a most expected result. The target is the overall treatment of the stochastic nature of the involved lifecycle processes and data, with emphasis on the methodology for the stochastic consideration of energy performance and not on specific methods for which data may even not yet be fully available. The stochastic simulation will be divided into the three phases: Pre-processing; Simulation; and Postprocessing. The first step (pre-processing) will identify the applicable stochastic variables, their ranges and scope, appropriate probability distribution functions and identification of the appropriate sampling methods. Stochastic issues will be considered with regard to climate/weather data, user behavior and occupancy profiles, and material properties. The second step, will handle the multiple simulations on the VEL cloud. Finally, the third step (pos-processing) will collect and process all the simulation results by performing an uncertainty analysis. However, to minimize the number of stochastic variables, a sensitivity analysis will be carried out before the uncertainty analysis.

\subsection{Virtual Energy Lab (VEL)}

To enable a holistic treatment of all relevant issues in the VEL, a flexible software architecture is being set up [17]. The information framework of the envisaged VEL platform will be based on an integrating platform ontology binding together the model of the facility represented as a standard BIM / IFC model and the multi-model environment of related external information resources, such as stochastic data (e.g. climate/weather information, occupancy profiles and material properties) and manufacturer product components provided in digital catalogues. The platform will comprise several types of services and applications, bounded together by a common Core Module that acts as the middleware providing the required data and functional interoperability. All other components of the targeted VEL prototype will be consistent with the identified use cases and may easily be extended or re-configured in accordance to specific preferences and building types. Accordingly, the main modules will include the:

1. Design Module, comprising a BIM-based CAD system, a product catalogue module for the selection and testing of new products and supporting tools capable to produce and export IFC model data.
2. Requirement Management Module, comprising a facility management system and related energy and cost estimate tools.

3. Common Access Module, providing a general-purpose interface to the VEL via a web application and enabling light-weight easy-to-do studies of building performance with regard to energy and life cycle costs.

4. Cloud Service Module, providing energy related analysis and simulation services and tools, a simulation model configurator for simultaneous alternative simulations of stochastic values, reporting tools for the generation of various kinds of aggregated reports for decision makers and access to all distributed information resources (product data catalogues, climate databases, BIM data etc.).

The final deliverable will be a prototype application using a generic approach. It will be supported by appropriate intelligent and adaptable access methods of a database variant manager in order to handle heterogeneous data that may be available from different sources (e.g. different climate/weather information, construction material properties or building element designs, occupancy and user profiles). The services framework will be open, flexible and scalable, implemented in the ISES VEL using currently available and commonly used communication protocols, in order to support an automated process for adapting this work and extending its applicability to different resources. An overview of the ISES generic approach and specific examples of commonly used configuration parameters is elaborated in [19].

\section{CASE STUDY}

The need for appropriate climate data for long term prediction of the annual energy performance of buildings (e.g. thermal comfort conditions, heating and cooling loads) with relatively low computational time has led to the development of the so-called Test Reference Years (TRYs) a term mainly used in Europe or Typical Meteorological Years (TMYs) a term mainly used in the USA. TRYs are commonly composed of hourly values for one year (12 typical meteorological months) rather than extreme conditions of measured weather data. A comprehensive overview of various weather data sets and methodologies is available in [20]. Building simulation software require TRYs that provide hourly data of solar radiation and other meteorological parameters for a period of one year (8760 hourly records), representing conditions considered to be typical over a long time-period (e.g. 10-, 20- or 30-years). A TRY is composed of individual (typical) months from the available data that are selected using different statistical criteria to preserve both typical mean values and variations for all the considered meteorological parameters. Accordingly, TRY data have natural diurnal and seasonal variations and represent a year of typical climate conditions for a location, preserving the main local weather characteristics, for example, typical cold or hot conditions, but consistent with the local long-term averages.

On the other hand, future climate conditions may be different. The development of stochastic weather data provides an opportunity to produce synthetic data representative of future conditions (e.g. warmer summer months) that may influence a building's lifecycle energy consumption [21] and 
even result in incorrect sizing of HVAC systems, misleading assessment of energy savings, or improper selection of design options [22]. However, availability of hourly data that account of the influence of climate change in the future is limited [23]. A simple approach to account for future climate changes is the so-called delta-method: start from a simple hourly weather file and apply a uniform monthly change (e.g. increase or decrease) of each parameter directly to the variable, over a monthly period. A more realistic approach to produce design weather data for building thermal simulations that accounts for future changes to climate is the socalled "morphing" method [24]. However, this method generates only one year of data for a given time period in the future, so there is some uncertainty in the projection. In addition, it requires the use of a climate model and the morphing technique relies on the baseline recorded weather being from the same time period as the baseline in the climate model.

As a first step, a simple investigation was performed for assessing the impact of different weather data on energy demand and building loads, and the time requirements for performing a series of building thermal simulations. The calculations are performed for a typical detached single family house, according to the Hellenic residential building typology [25]. The house has a total floor area of $363 \mathrm{~m}^{2}$ and a volume of $1200 \mathrm{~m}^{3}$ consisting of an underground basement and two floors. Constructed in the 90's, the building is a representative example of single family houses built during the first period of the implementation of the first Hellenic building thermal insulation regulation that was introduced in 1980. During the first period of implementation (1980-2000) the regulation mandates were not fully enforced in practice. Accordingly, the walls and roof are insulated in accordance to the regulation, but the load bearing structure is noninsulated reinforced concrete, resulting in a value for the mean thermal transmittance $\left(\mathrm{U}_{\mathrm{m}}\right)$ equal to $1.15 \mathrm{~W} / \mathrm{m}^{2} \cdot \mathrm{K}$ for the building. The double glazed windows with a thermal transmission coefficient of $2.80 \mathrm{~W} / \mathrm{m}^{2} \cdot \mathrm{K}$ correspond to a $10 \%$ of the external facade area and $14 \%$ of the heated floor area. Partial shading is provided by structural elements (balconies, roof projection) acting as overhangs on the southeast and northwest facade. Residential buildings in Greece are naturally ventilated; therefore, no mechanical ventilation system is defined in the building model. An average infiltration rate of 0.6 air changes per hour is considered in this study. Internal heat gains due to the presence people and their activities are not taken into account. The time requirements to setup this simple building model in the energy simulation package [26] were about three working days.

A total number of 90 hourly simulations were performed using TRNSYS [26] with annual weather data over 30 years (1975-2004) and an available TRY for Athens (Greece) that has been derived from this 30year historic data. The TRY includes hourly global and diffuse solar radiation on horizontal, temperature and relative humidity, wind speed and direction. The time requirements to manually prepare the input annual weather data for the simulations required a total of one working day.

Using the (1975-2004) annual weather data constitutes a best case scenario, since this time series is the same population that the TRY was derived from. However, extremes or other major deviations of the outdoor air temperature may be possible using different annual weather data that may also have an impact on the TRY. Accordingly, to account for such possible variations if one considers, for example, more recent annual weather data or possible changes of future climate conditions, a simple delta-method was used to alter the mean outdoor air temperature by using different temperature increments, as elaborated in the following discussion.

The hourly simulations provide the energy demand $(\mathrm{kWh})$ to reach the desirable indoor conditions $\left(20^{\circ} \mathrm{C}\right.$ in winter and $26^{\circ} \mathrm{C}$ in summer, without simultaneous heating or cooling) for every hour throughout the year ( 8760 hours). The hourly heating demand over the winter months (October through April; $\mathrm{N}=6552$ hours) and the hourly cooling demand over the summer months (May through September; $\mathrm{N}=2208$ hours) are summed to derive the corresponding energy demand for satisfying the sensible (heating and cooling) energy needs. The values are finally normalized per unit floor area $\left(\mathrm{m}^{2}\right)$.

Since the TRY is composed of hourly values of a specific month (i.e. considered typical) from the time series (each month may be extracted from a different year), there will be deviations from the corresponding hourly values of the outdoor air temperature from year to year. As illustrated in (Fig. 1), there are strong variations for the building heating and cooling energy demand throughout the years. Relative to the TRY results, the calculated heating energy demand varies from a minimum difference of $0.8 \%$ to a maximum difference of $26 \%$ and the cooling energy demand from $1 \%$ to $58 \%$, respectively. The mean difference is $9.3 \%$ for the calculated heating energy demand and $22.8 \%$ for cooling

Annual variations of calculated energy demand are influenced by various factors including differences in the outdoor air temperature, solar radiation that affects direct solar gains (decreasing heating loads in winter and increasing cooling loads in summer), along with their duration and persistence (i.e. consecutive hours) during a simulation period. There are complex and coupled phenomena that involve, for example, the building's thermal inertia and impact the calculated hourly energy demand from the simulation tool. Although there is no single criteria that can fully explain all the observed differences, commonly used parameter include the Heating Degree Days (HDD). To a great extent, the heating energy demand of a given building is proportional to the number of HDD that are calculated as the sum of the differences between a base temperature (usually $18^{\circ} \mathrm{C}$ ) and the average outdoor air temperature for the day. Higher HDD values imply periods with lower outdoor air temperatures and thus a higher heating demand. As illustrated in (Fig. 1), relative to the TRY, the annual variations in winter are within $\pm 20 \%$ and are partially explained by the differences of the HDD for a given year relative to the TRY (1158 HDD). Overpredictions in the heating energy demand ranged from $0.8 \%$ in 2003 (1156 HDD) to $19.9 \%$ in 1991 (1312 HDD). Underpredictions ranged from $-1.5 \%$ in 1981 (1118 HDD) to $-25.8 \%$ in 1999 (891 HDD).

A similar parameter, the cooling degree hours $(\mathrm{CDH})$, has also been used to reflect the cooling energy demand in summer. In this case, the number of $\mathrm{CDH}$ is calculated as the difference between a base temperature (usually $26^{\circ} \mathrm{C}$ ) and 

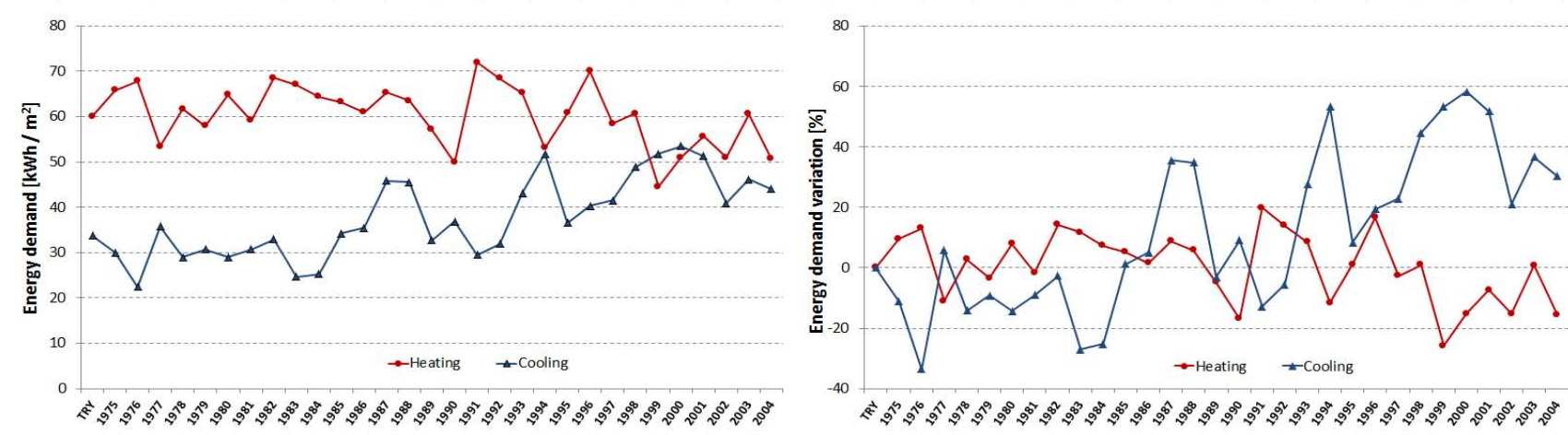

Fig. (1). Calculated annual heating and cooling energy demand per unit floor area $\left(\mathrm{kWh} / \mathrm{m}^{2}\right)$ for the entire time series (left) and difference (\%) of calculated annual energy demand (heating and cooling) for the entire time series against the TRY (right).

the average outdoor air temperature for the hour. To some extent, higher $\mathrm{CDH}$ values would imply periods with higher outdoor air temperatures that lead to higher cooling demand. However, the main driving mechanism associated with cooling energy demand is the solar radiation and direct solar heat gains, although high outdoor air temperatures are commonly associated with high solar radiation availability. Relative to the TRY (4283 CDH), using the annual weather data the overpredictions in the cooling energy demand ranged from $1.2 \%$ in $1985(4965 \mathrm{CDH})$ to $58.3 \%$ in $2000(9003 \mathrm{CDH})$. Underpredictions ranged from $-3.0 \%$ in $1989(3787 \mathrm{CDH})$ to $-33.5 \%$ in 1976 (3778 CDH).

Regarding the peak heating and cooling loads, a similar trend is produced from the simulation results, as shown in (Fig. 2). In this case, the calculated peak heating load varies from a minimum difference of $0.8 \%$ to a maximum difference of $46 \%$ and the peak cooling load from $1 \%$ to $34 \%$, respectively. The mean difference is $17.7 \%$ for the calculated peak heating load and $11.7 \%$ for the calculated peak cooling load over the entire time series. Again, since the methodology for deriving the TRY is based on mean monthly data, thus considering typical conditions, it misses possible low or high ambient air temperature extremes (i.e. worst-case conditions occurring at a location) that occur from year to year. Accordingly, TRYs should not be used for sizing heating or cooling systems and their components. As illustrated by the simulation results, the peak loads in winter using the annual weather data were almost consistently higher than the corresponding TRY value, which implies that the heating system would not meet the peak heating loads during the coldest periods. For the winter periods, the minimum ambient air temperature in the TRY was $1.1^{\circ} \mathrm{C}$, while for the annual weather data it ranged from $-4.5^{\circ} \mathrm{C}$ in 2004 to $4.1^{\circ} \mathrm{C}$ in 1984 . The corresponding results for the summer periods show greater fluctuations from year to year. The maximum ambient air temperature in the TRY was $37.6^{\circ} \mathrm{C}$, while for the annual weather data it ranged from $33.9^{\circ} \mathrm{C}$ in 1976 to $43.3^{\circ} \mathrm{C}$ in 2000. Clearly, both cases (energy demand and peak loads) reflect the importance of the input weather and climate data in building load calculations and consequently to HVAC design and equipment selection.

According to the European Environment Agency (EEA) as a result of climate change, the mean outdoor air temperature for south Europe is expected to increase by $0.4^{\circ} \mathrm{C}$ over the period of 2021 to 2050 and by $2.5^{\circ} \mathrm{C}$ over 2071 to 2100 [27]. An urban environment may also exhibit similar order of magnitude temperature variations compared with data from meteorological stations. In addition, based on historic weather data for Athens [28], periodic heat waves have also resulted to maximum temperature increases of about $2-3^{\circ} \mathrm{C}$. Based on EEA estimates, several simulations for the cooling period were performed using modified TRYs according to the simple delta-method with a mean outdoor air temperature increment of $0.1^{\circ} \mathrm{C}$ extending up to $3^{\circ} \mathrm{C}$, as an exercise, to account for long term uncertainties. A total of 30 modified TRYs, i.e. M1-M30, were derived. The results are illustrated in (Fig. 3), for the TRY and each of the modified TRYs. For example, M1 corresponds to the modified TRY cooling period data by $+0.1^{\circ} \mathrm{C}$, while $\mathrm{M} 30$ corresponds to the modified TRY cooling period data by $+3.0^{\circ} \mathrm{C}$.

Cooling demand and peak cooling load have an almost linear increase with mean temperature increase, as illustrated with the modified TRYs (M1-M30). Calculated cooling energy demand varies from $2.5 \%$ to $74 \%$ (relative to the TRY), while peak cooling load varies from $0.5 \%$ to $19 \%$. Taking into account the peak load variation for the various mean temperature increase estimates, it appears that for this building typology one may expect only small deviations for HVAC equipment selection, at least for a temperature increase of up to $0.5^{\circ} \mathrm{C}$. Although these preliminary results illustrate the anticipated variations of cooling energy demand and peak loads as a result of various mean temperature increase predictions, further investigation is required since the current study doesn't take into account the increase in the frequency of occurrence of extreme conditions, day and night variations, and their duration. This kind of calculations will be facilitated by exploiting the VEL cloud capabilities to expedite the necessary simulations.

\section{CONCLUSION}

A Virtual Energy Laboratory (VEL) that is currently under development is anticipated to increase by an order of magnitude the quality of building energy efficient design. The focus of the ongoing work is on multi-model design and testing, stochastic lifecycle analysis and simulation in combination with new supporting ontology and interoperability tools and services, and respective re-engineering of existing tools. The demonstration of the time requirements for 

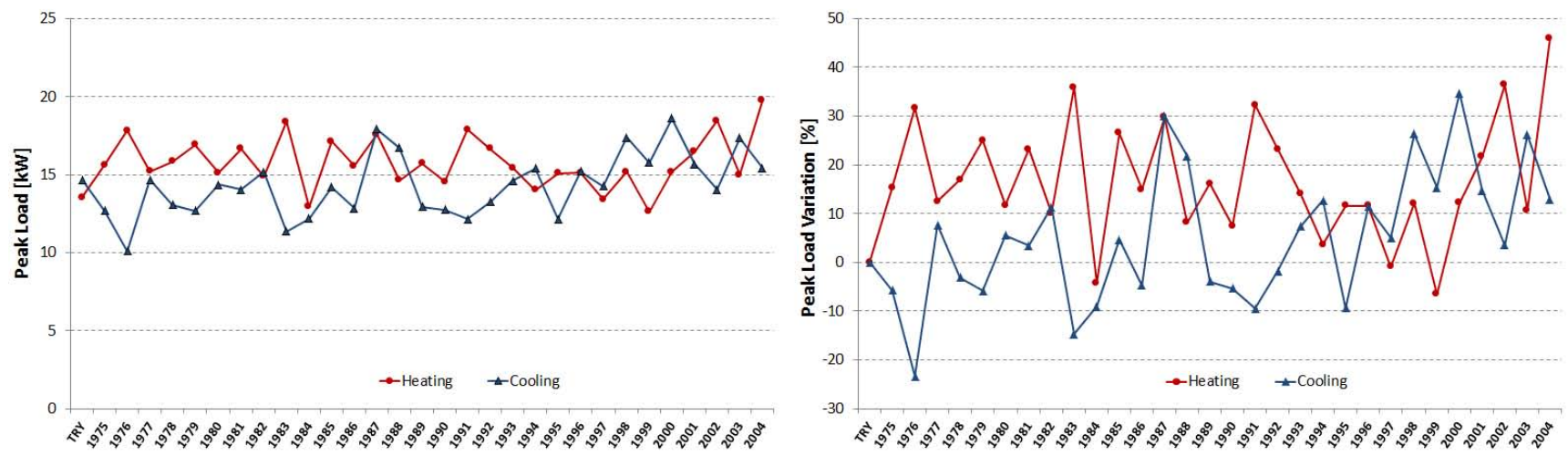

Fig. (2). Calculated annual peak heating and cooling loads $(\mathrm{kW})$ for the entire time series (left) and difference (\%) of calculated annual peak loads for the entire time series against the TRY (right).
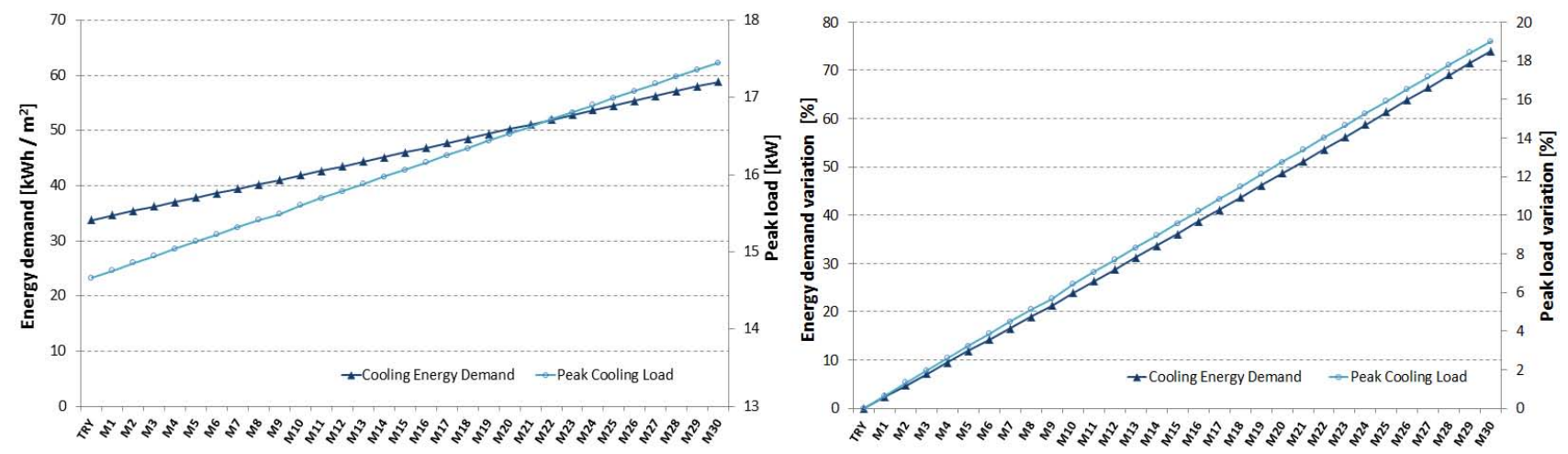

Fig. (3). Calculated cooling energy demand per unit floor area $\left(\mathrm{kWh} / \mathrm{m}^{2}\right)$ and peak cooling load $(\mathrm{kW})$ for the 30 modified TRY (M1-M30) data (left) and variation (\%) of calculated cooling energy demand and peak load against the TRY (right).

preparing a simple building model for thermal simulations and the effort to investigate the impact of various input weather data, revealed the burdens of existing procedures. A total of four working days were mandated for a typical house, with three thermal zones, working with paper drawings in order to extract the necessary information and manipulate the weather data. An energy enhanced BIM that will be incorporated in the VEL is expected to provide a coherent approach for enhancing BIM data with the necessary information from heterogeneous external data sources and facilitate the integration of various models commonly used in holistic building design and simulations.

A simple case study revealed the range of anticipated differences in simulations for calculating the building energy demand and peak loads, using a TRY and measured annual weather data. Given that a TRY represents a year of typical climatic conditions for a location, it may be used for estimating the average (typical) energy demand of a building. However, a TRY does not account for specific variations that influence energy demand or near extreme conditions of actual (measured) weather that determine the peak loads. Accordingly, using a 30year time series of annual weather data and the corresponding TRY for Athens, the simulation results revealed significant discrepancies on an annual basis. The mean difference for the heating energy demand was $9.3 \%$ and $22.8 \%$ for cooling, while for the peak loads it reached $17.7 \%$ for heating and $11.7 \%$ for cooling. The corresponding results for specific years ranged between $-25.8 \%$ to
$19.9 \%$ for heating energy demand and from $-33.5 \%$ to $58.3 \%$ for cooling demand. For the peak heating load, the results for specific years ranged between $-6.6 \%$ to $46.0 \%$ and for the peak cooling load from $-23.4 \%$ to $34.7 \%$.

The simple delta-method was used to illustrate the impact of possible future climate long term uncertainties, by using modified TRYs with a mean outdoor air temperature increment of $0.1^{\circ} \mathrm{C}$ extending up to $3^{\circ} \mathrm{C}$. Relative to the TRY, the calculated cooling energy demand varies from $2.5 \%$ to $74 \%$, while peak cooling load varies from $0.5 \%$ to $19 \%$. One may expect only small deviations for sizing HVAC equipment, at least for a temperature increase of up to $0.5^{\circ} \mathrm{C}$. The assessment may be improved by using a climate model following the "morphing" method. Other issues that may be of interest include a sensitivity analysis of additional weather parameters (e.g. wind velocity and direction, incident solar radiation), to account for possible variations of the microclimate, especially in dense urban environments that exhibit large variations compared with data from meteorological stations. Finally, the overall stochastic analysis of key parameters (e.g. climate/weather data, occupancy, material properties) will eventually provide useful insights for assessing the uncertainties in building energy performance and load calculations.

\section{CONFLICT OF INTEREST}

The author(s) confirm that this article content has no conflicts of interest. 


\section{ACKNOWLEDGEMENT}

This work was performed in the context of the European research project "Intelligent Services for Energy-Efficient Design and Life Cycle Simulation - ISES" (http://ises.euproject.info/) that is co-financed by the European Commission (Seventh framework Programme, Information Society and Media Directorate-General). The project is coordinated by the Technische Univeritaet Dresden (Germany) and participating organizations include: Granlund Oy (Finland), Univerza V Ljubljana (Slovenia), Sofistic Hellas A.E. (Greece), Nyskopunarmidstod Islands (Iceland), National Observatory of Athens (Greece), Leonhardt Andrä Und Partner Beratende Ingenieure Vbi GmbH (Germany) and Trimo Inzeniring In Proizvodnja Montaznih Objektov (Slovenia).

\section{REFERENCES}

[1] F. Leite, A. Akcamete, B. Akinci, G. Atasoy, and S. Kiziltas, "Analysis of modeling effort and impact of different levels of detail in building information models", Automation in Construction, vol. 20, no. 5, pp. 601-609, 2011.

[2] T.V. Rasmussen, "Retrofitting listed buildings: measures, savings and requirements", The Open Construction and Building Technology Journal, vol. 5, pp. 174-181, 2011.

[3] E.G. Dascalaki, S. Kontoyiannidis, C.A. Balaras, and K.G. Droutsa, "Energy certification of hellenic buildings: First findings", Energy \& Buildings, vol. 65, pp. 429-437, 2013.

[4] R. Schüle, V. Aydin, J. Fischer, T. Madry, S. Thomas, D. Becker, N. Bader, C. Egger, J. Kaselofsky, T. Koska, C. SchäferSparenberg, L. Tholen, R. Priewasser, M. Kloiber, N. Borg, P. Schilken, and D. Bourges, Improving and Implementing National Energy Efficiency Strategies in the EU Framework, 123 p., Energy Efficiency Watch, June 2013. Available from: http://www.eceee.org/all-news/news/news_2013/2013-08-30a, accessed October 16, 2013.

[5] EPBD Recast, European Directive 2010/31/EU of the European Parliament and of the Council of 19 May 2010 on the energy performance of buildings, Official Journal of the European Union, 2010. Available from: http://ec.europa.eu/energy/efficiency/buildings/buildings_en.htm, accessed October 16, 2013.

[6] European Commission, Standardisation Mandate $M / 480$ to the European Committee for Standardization, Brussels, December 2010. Available from: http://ec.europa.eu/energy/efficiency/buildings/doc/2010 mandate 480 en.pdf, accessed October 16, 2013.

[7] EPA, Building and Energy Codes, US Environmental Protection Agency. Available from: http://www.epa.gov/region9/greenbuilding/building-codes.html, accessed October 16, 2013.

[8] bEQ, Building Energy Quotient, Atlanta: ASHRAE. Available from: http://www.buildingenergyquotient.org

[9] DOE, Zero Energy Buildings, Building Technologies Program, US Department of Energy. Available from: http://zeb.buildinggreen.com, accessed October 16, 2013.

[10] N.W. Alnaser, "Towards Sustainable Buildings in Bahrain, Kuwait and United Arab Emirates", The Open Construction and Building Technology Journal, vol. 2, pp. 30-45, 2008.

[11] D. Conover, C.S. Barnaby, D. Crawley, C. Gulledge, S. Hagan, R. Hitchcock, D. Knight, S. Rosen, B. Emtman, M. Palmer, G. Holness, C. Wilkins, and D. Iverson, An Introduction to Building Information Modeling, Atlanta: ASHRAE, 2009. Available from: http://cms.ashrae.biz/bim/pdf/BIMGuide_Rev_110309.pdf, accessed October 16, 2013.
[12] National Building Information Modeling Standard Part-1: Overview, Principles and Methodologies, Final Report, National Institute of Building Sciences, buildingSMART alliance, 2007. Available from: http://www.wbdg.org/pdfs/NBIMSv1_p1.pdf, accessed October 16, 2013.

[13] G. Lee, R. Sacks, and C.M. Eastman, "Specifying parametric building object behavior for a building information modeling system", Automation in Construction, vol. 15, no. 6, pp. 758-763, 2006.

[14] C. Eastman, P. Teicholz, R. Sacks, and K. Liston, BIM Handbook: A Guide to Building Information Modeling for Owners, Managers, Designers, Engineers and Contractors, Hoboken: New Jersey, John Wiley \& Sons, 2008

[15] S.F. Bruning, "BIM test at ASHRAE HQ", ASHRAE Journal, vol. 53, no. 4, pp. 28-36, 2011.

[16] D. Knight, S. Roth, and S.L. Rosen, "Using BIM in HVAC design”, ASHRAE Journal, vol. 52, no. 6, pp. 24-32, 2010.

[17] M. Kavcic, C. Balaras, G. Gudnasson, R. Guruz, J. Kaiser, P. Katranuschkov, T. Laine, T. Mansperger, T. Pappou, B. Cerne, and A. Zahedi, ISES Deliverable D1.1: Gap Analysis, ISES Consortium, Brussels, 2012. Available from: http://ises.eu-project.info/documents/ISES-D1.1.pdf, accessed October 16, 2013.

[18] A. Zahedi-Khameneh, R.J. Scherer, and G. Gudnasson, 2012. ISES Deliverable D2.1, Overall Stochastic Approach for the Virtual Energy Lab Platform, ISES Consortium, Brussels. Available from: http://ises.eu-project.info/documents/ISES-D2.1.pdf, accessed October 16, 2013

[19] G. Gudnason, K. Baumgärtel, A. Zahedi Khameneh, P. Katranuschkov, R. Guruz, C. Balaras, and B. Protopsaltis, ISES Deliverable D4.2: Prototype of the intelligent search, access and interoperability services to the energy-related ICT, ISES Consortium, Brussels, 2013. Available from: http://ises.eu-project.info/documents/ ISES-D4.2.pdf, accessed October 16, 2013.

[20] D.B. Crawley, "Which weather data should you use for energy simulations of commercial buildings?", ASHRAE Transactions, vol. 104, no. 2, pp. 498-515, 1998 .

[21] P. de Wilde, and D. Coley, "The implications of a changing climate for buildings", Building and Environment, vol. 55, pp. 1-7, 2012.

[22] T.J. Williamson, E. Erell, and V. Soebarto, "Assessing the error from failure to account for urban microclimate in computer simulation of building energy performance", in Proceedings of the 11th International IBPSA Conference, Glasgow, Scotland, 2009, pp. 497-504.

[23] D.R.S. Williams, L. Elghali, and R.C. Wheeler, "Use of stochastic weather generators in the projection of building energy demand in a changing climate", in Proceedings of the World Renewable Energy Congress, Linkoping, Sweden, 2011, pp. 2056-2063.

[24] S. Belcher, J. Hacker, and S. Powell, "Constructing design weather data for future climates", Building Services Engineering Research and Technology, vol. 26, no. 1, pp. 49-61, 2005.

[25] E.G. Dascalaki, K.G. Droutsa, C.A. Balaras, and S. Kontoyiannidis, "Building typologies as a tool for assessing the energy performance of residential buildings - A case study for the hellenic building stock", Energy and Buildings, vol. 43, no. 12, pp. 34003409, 2011.

[26] TRNSYS, Version 16, Simulation Studio, Solar Energy Laboratory, University of Wisconsin, Madison, WI, 2005.

[27] P. van der Linden, and J.F.B. Mitchell, Eds, Climate change and its impacts at seasonal, decadal and centennial timescales, ENSEMBLES, Brussels, 2009

[28] D. Founda, and C. Giannakopoulos, "The exceptionally hot summer of 2007 in Athens, Greece - A typical summer in the future climate?", Global and Planetary Change, vol. 67, no. 3-4, pp. 227236,2009

(C) Balaras et al.; Licensee Bentham Open.

This is an open access article licensed under the terms of the Creative Commons Attribution Non-Commercial License (http://creativecommons.org/licenses/by-nc/3.0/) which permits unrestricted, non-commercial use, distribution and reproduction in any medium, provided the work is properly cited. 